\title{
Symmetric Random Biometric Key (Srbk) Based Cryptography
}

\author{
S.Pavithra, P.Muthu Kannan
}

\begin{abstract}
In this paper, we propose a novel cryptographic algorithm namely Symmetric Random Biometric key (SRBK) algorithm. The key for this SRBK algorithm is obtained from two biometric features namely ear and lip. The key generated are flexible and can be altered based on the type of algorithm used. We also consider Advanced encryption standard (AES)algorithm for comparison with SRBK algorithm and finally it was proved that SRBK algorithm is better than AES algorithm on selected parameters.
\end{abstract}

Key words: Bi-modal biometrics, AES, Key generation.

\section{INTRODUCTION}

Security plays a vital role in transferring huge amount of data across the internet where the information is not safe guarded by any medium. Cryptography is an eminent component in communication which ensures secure transmission and reception takes place between authorized parties. The proper selection of cryptographic algorithm is important for security, efficiency and other parameters. In this paper, a novel method is proposed to generate keys using biometric features like ear and lip. The detailed generation of key by bi-modal method is discussed in [9]. Biometrics is an analysis from human physical and behaviour characteristics. Though many methods are available, we use human EAR and LIP because of its unique features for generating binary values(keys). The advantage of using this biometric feature is that the key generated is flexible. The bits generated at the final stage can be obtained based on the algorithm we use. In this paper, the biometric key is applied to AES algorithm and also to the novel method proposed. In AES, the key length is 128 bits, whereas in SRBK, the length is 16 bits.

\subsection{GENERATION OF BIOMETRIC KEYS}

Here the initial set of values for keys in terms of 16 bytes are generated from biometric features (Ear and Lip). Two features are taken as reference and 128 bits are generated from the two features.

The steps followed in key generation are:

$>$ Input image

$>$ Conversion from RGB to GRAY-

$>\quad$ Filtering-various filters were applied and analysed to know the better noise removal filter

$>$ Enhancement- Tonal regularisation

Revised Manuscript Received on August 14, 2019.

S.Pavithra, Research scholar, Saveetha Institute of Medical And Technical Sciences (SIMATS), Chennai, Tamilnadu, India(email: pavithrra1286@gmail.com)

Dr.P.Muthukannan, Professor, Saveetha School of Engineering, Saveetha Institute of Medical and Technical Sciences, Chennai, Tamilnadu, India(email: muthukannan@saveetha.com)
$>$ Image reshaping- Mean level of the pixel are adjusted

$>$ Extraction- concentrating and extracting selective feature on the image

$>$ Concatenation- Gradient calculation

$>$ Gradient image

$>\quad$ Sorting-re-arranging the values

$>\quad$ Key generation. - binary value is generated as key.

The detailed method of key generation from Ear feature is discussed in [9].

The most popular standard algorithm which is widely used in today's scenario is AES algorithm. It is found to be several times faster than the triple-DES algorithm.

The features of AES are as follows

$>\quad$ Symmetric key /block cipher.

$>$ Based on number of rounds, the key length is varied.

$>\quad$ Fast and stronger than triple-DES.

$>\quad$ Gives the entire specification and design details.

$>\quad$ Can be implemented in software tools.

\section{BIOMETRIC KEY IN AES}

The key obtained from biometric feature is flexible and therefore can be applied to AES based on number of rounds. The overview of key size and rounds is shown in table 1 .

Table 1: Relationship between key size and number of rounds in AES.

\begin{tabular}{|c|c|}
\hline $\begin{array}{c}\text { KEY } \\
\text { SIZE }\end{array}$ & $\begin{array}{c}\text { NO.OF } \\
\text { ROUNDS }\end{array}$ \\
\hline 128 & 10 \\
\hline 192 & 12 \\
\hline 256 & 14 \\
\hline
\end{tabular}

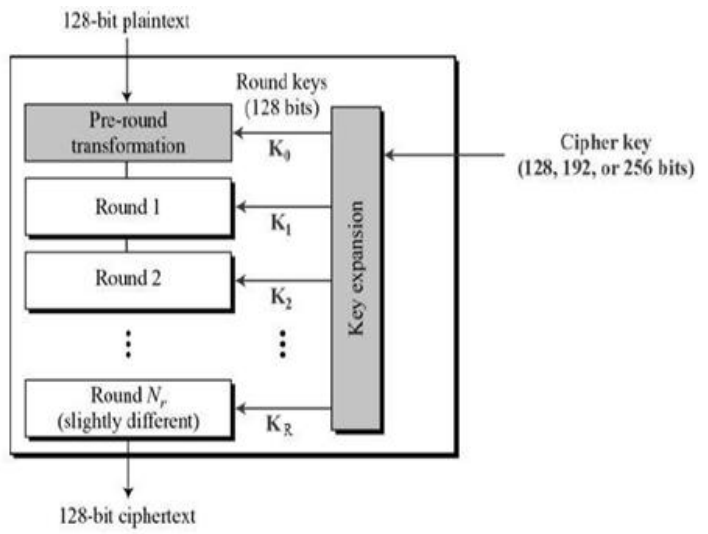

Fig 1: The general schematic of AES algorithm [3]

Published By:

Blue Eyes Intelligence Engineering

\& Sciences Publication 


\subsection{AES ANALYSIS USING BIOMETRIC KEYS}

The keys obtained from ear and lip biometric features are given as input(key) to the encryption /decryption process of AES algorithm. The 128- bit key and 10 round operation is performed. The results are shown below.

\subsubsection{Encryption:}

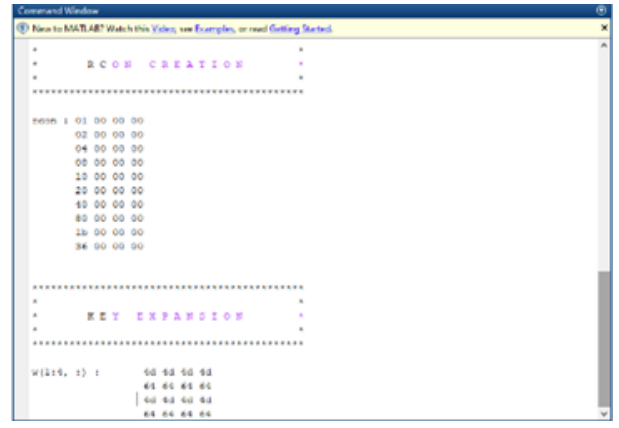

Fig 2: biometric key used in AES for Pre-round

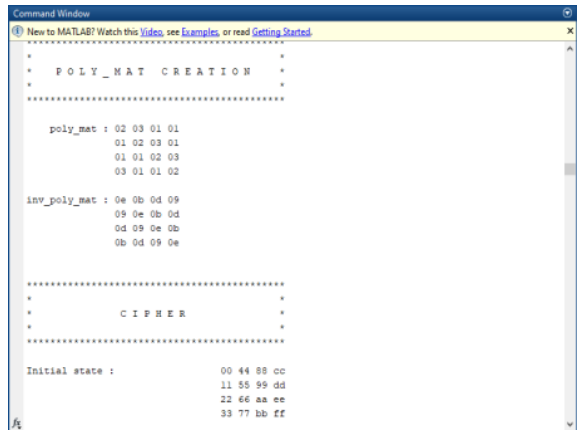

Fig 3: Cipher taken for process.

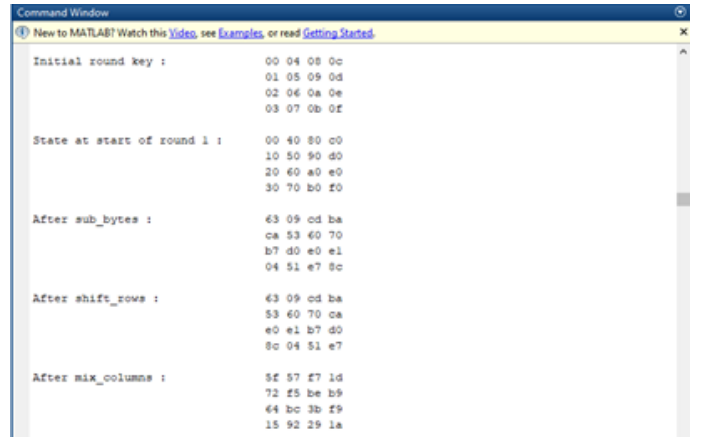

Fig 4: Initial round 1 process

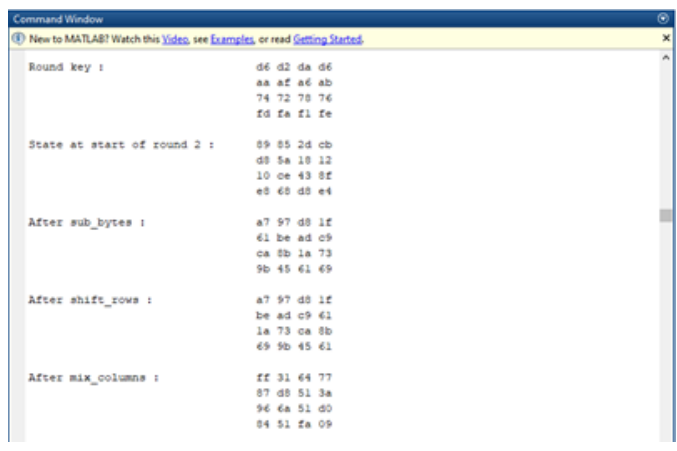

Fig 5: Round 2 process

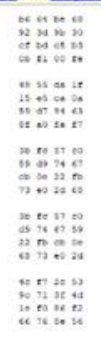

Fig 6: Round 3-AES

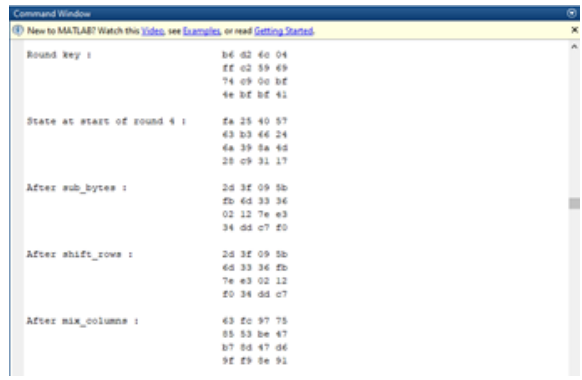

Fig 7: Round 4-AES

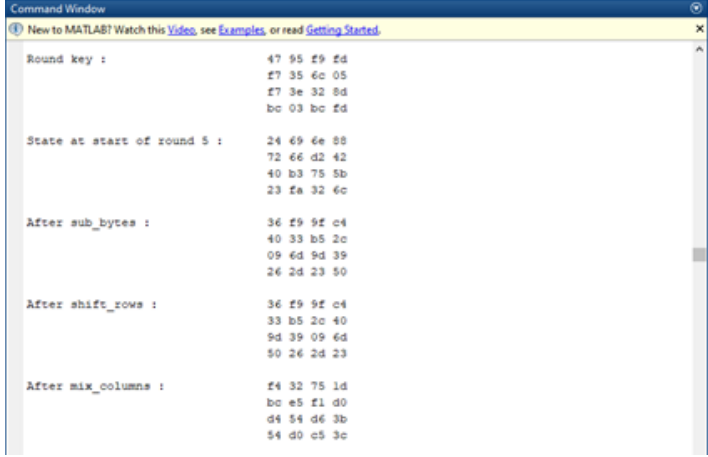

Fig 8: Round 5-AES

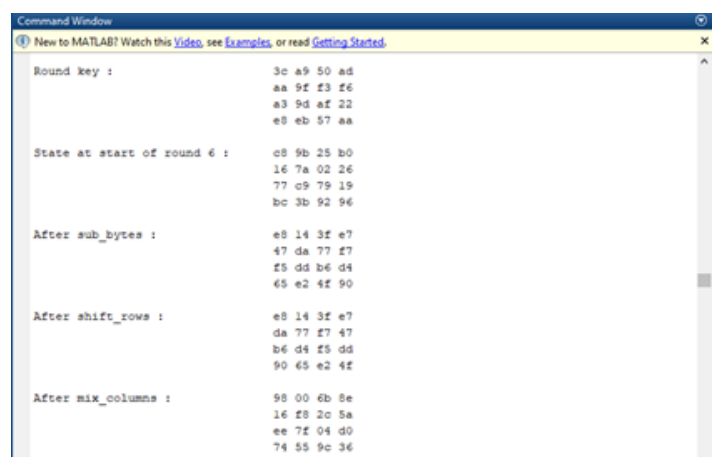


Fig 9: Round 6-AES

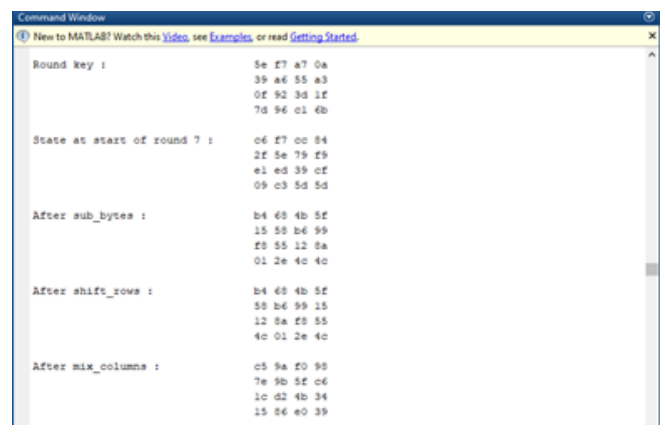

Fig 10: Round 7-AES

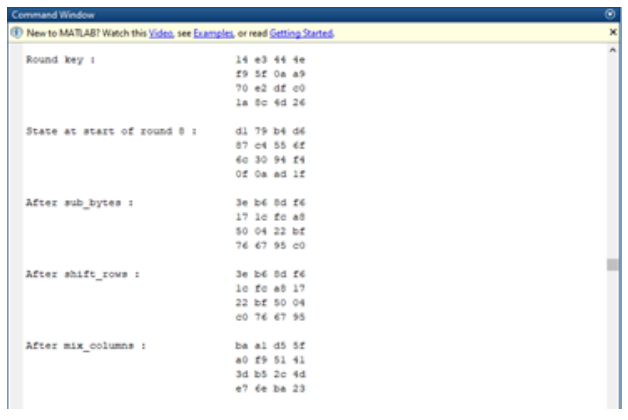

Fig 11: Round 8-AES

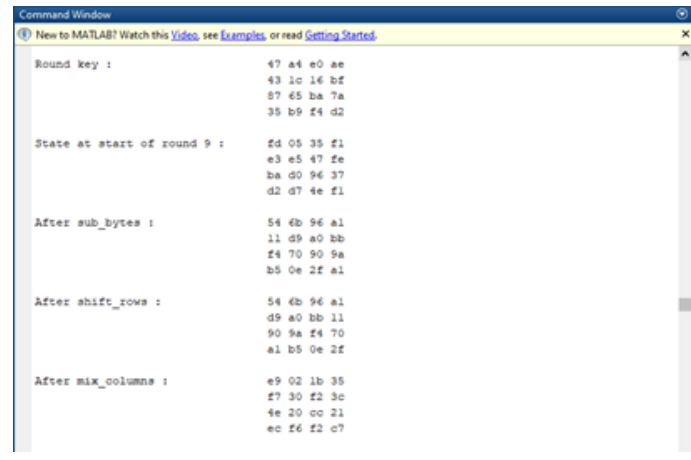

Fig 12: Round 9-AES

\begin{tabular}{|c|c|}
\hline Command Window & \\
\hline (1) New to MATLBB? Watch this & 5 or read Getting Sturted. \\
\hline Round key : & 542010 be \\
\hline & 99859320 \\
\hline & 3257 ed 97 \\
\hline & d. $68 \mathrm{ge} 4 \mathrm{e}$ \\
\hline State at start of : & $b d=2 \quad O b \quad 8 b$ \\
\hline & te bs 6110 \\
\hline & 707721 b6 \\
\hline & 3d $9 e$ be 89 \\
\hline After sub_byces: & $7 \mathrm{~d} 992 \mathrm{~b} 3 \mathrm{~d}$ \\
\hline & It 45 ef $\mathrm{ca}$ \\
\hline & $10 \mathrm{t5} \mathrm{td}$ ie \\
\hline & 27 ob 98 a 7 \\
\hline After shift_rows : & $7 \mathrm{a} 992 \mathrm{~b} 3 \mathrm{~d}$ \\
\hline & d5 ef ea $g t$ \\
\hline & td 4e 10 t5 \\
\hline & a7 27 ob $9:$ \\
\hline
\end{tabular}

Fig 13: Final round 10-AES

\begin{tabular}{|c|c|}
\hline Command Window & \\
\hline (9) New to MATLAB? W. & so or red Gerting Shated \\
\hline Round key : & 13 e 3 : 3 4d \\
\hline & $1194072 \mathrm{~b}$ \\
\hline & 10 4a $\$ 730$ \\
\hline & $7 t 1780<5$ \\
\hline Final state : & $696 \mathrm{ads} 70$ \\
\hline & $c t 7 b$ ad $b 4$ \\
\hline & e0 $04 \mathrm{~b}^{\circ} \mathrm{cs}$ \\
\hline & $\mathrm{d8} 30 \$ 0 \mathrm{sa}$ \\
\hline
\end{tabular}

Fig 14: Final key at the end of encryption and cipher text

\subsubsection{Decryption:}

The key and cipher text obtained from the final step of encryption process is given as input to the decryption. Fig 15 shows the first step in decryption and fig 16 shows the final key and plain text obtained.

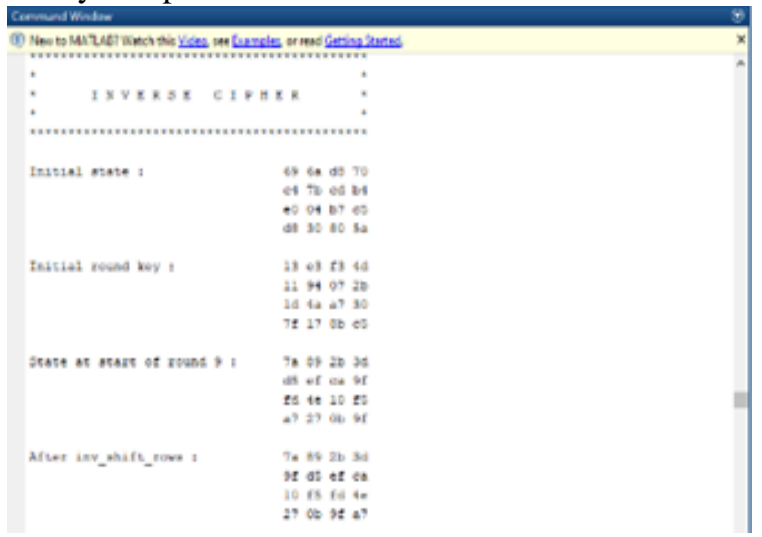

Fig 15: Decryption process- key and cipher text to plain text conversion

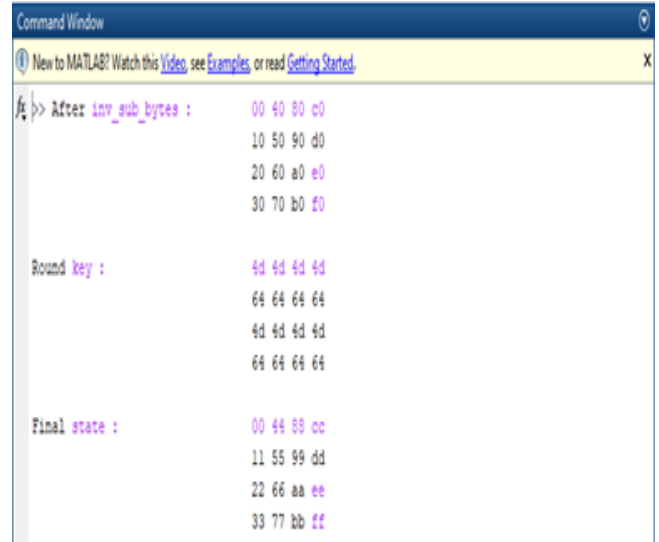

Fig 16: Final key and plain text at the end of decryption

In today's scenario, AES is widely used and accepted for hardware and software implementation. Till date, no practical cryptographic attack has been identified or reported. Additionally, AES has built -in- key flexibility which improves the overall advantage of the process. However, similar to DES, AES security is assured only if it is correctly implemented with the proper key management techniques. [2]

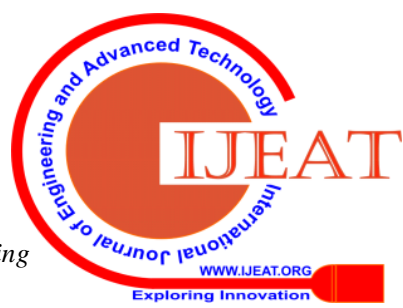


III. THE PROPOSED NOVEL METHOD: SYMMETRIC RANDOM BIOMETRIC KEY (SRBK)

\subsection{ENCRYPTION}

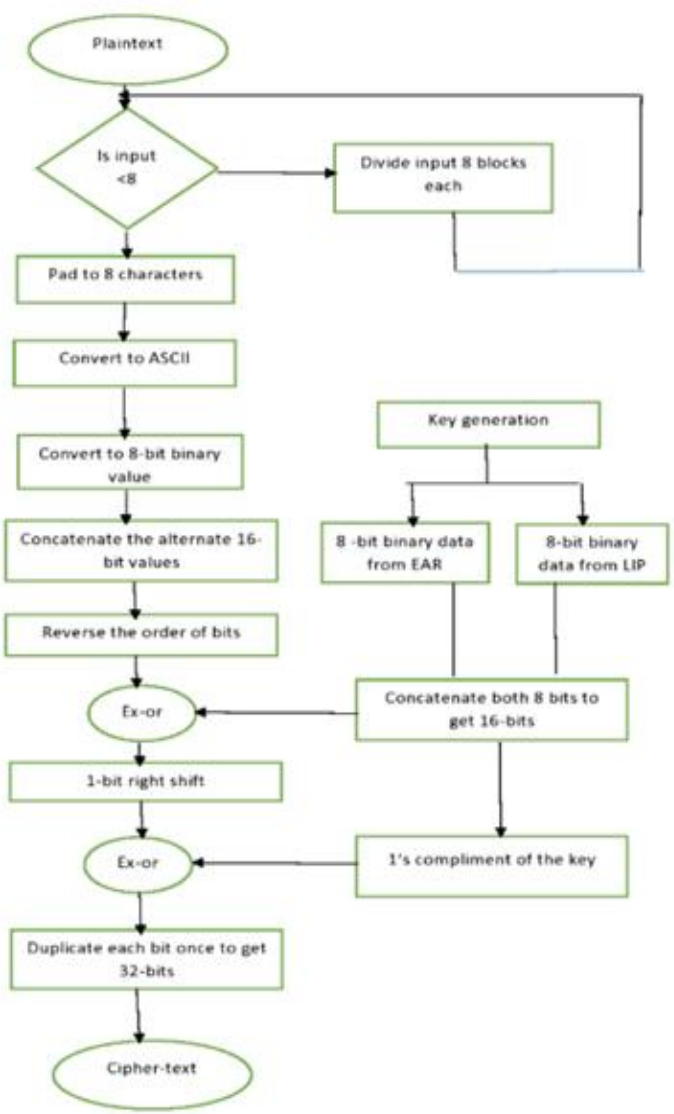

Fig 17: Flow chart of SRBK Encryption

Step 1: Initial data of size multiple of 8 is taken, if necessary do padding.

Step 2: Data is divided into 8 characters each
Step 3: Convert into its corresponding ASCII equivalent. Step 4: Concatenate the alternate set of binary values Step 5: Reverse the order of bits from step 4

Step 6: Bringing the concatenated biometric key from ear and lip

Step 7: Ex-or the result of step 5 and step 6

Step 8: Perform 1-bit right shift with result obtained from step 7

Step 9: 1's compliment the values of step 6

Step 10: Ex-or the result of step 8 and step 9

Step 11: Duplicating each bit once to get 32-bit cipher text

\begin{tabular}{|c|c|c|c|c|c|c|c|c|}
\hline PLAIN TEXT & 5 & $\mathrm{U}$ & C & C & $\bar{E}$ & 5 & $E$ & 5 \\
\hline ASCII & 83 & 85 & 67 & 67 & 69 & 83 & 69 & 83 \\
\hline BINARY VALUE & 1010011 & 1010101 & 1000011 & 1000011 & 1000101 & 1010011 & 1000101 & 1010011 \\
\hline $\begin{array}{l}\text { CONCATENATE THE } \\
\text { ALTERNATE BITS }\end{array}$ & 101001101000011 & 101010101000011 & 100010101000101 & 101001101010011 & & & & \\
\hline $\begin{array}{l}\text { REVERSE THE } \\
\text { ORDER }\end{array}$ & $\begin{array}{r}110000101100101 \\
0\end{array}$ & 1100001010101010 & 1010001010100010 & 1100101011001010 & & & & \\
\hline $\begin{array}{l}\text { KEY CONCATENATE } \\
\text { FROM EAR AND LIP }\end{array}$ & $\begin{array}{l}010011100110010 \\
0\end{array}$ & & & & & & & \\
\hline $\begin{array}{l}\text { KEY'S } \\
\text { COMPLIMENT }\end{array}$ & $\begin{array}{l}101100011001101 \\
1\end{array}$ & & & & & & & \\
\hline $\begin{array}{l}\text { XOR-ING THE } \\
\text { REVERSE BITS WITH } \\
\text { KEY }\end{array}$ & $\begin{array}{l}100011001010110 \\
0\end{array}$ & 1000110011001110 & II10111011000110 & 1000010010101110 & & & & \\
\hline $1 \mathrm{BIT}$ RIGHT SHIFT & $\begin{array}{l}010001100101011 \\
0\end{array}$ & 0100011001100111 & 0111011101100011 & 0100001001010111 & & & & \\
\hline $\begin{array}{l}\text { XOR-ING WTTH } \\
\text { KEY'S } \\
\text { COMFLIMENT }\end{array}$ & ${ }_{1}^{111101111100110}$ & 1111011111111100 & 1100011011111000 & 1111001111001100 & & & & \\
\hline $\begin{array}{l}\text { DUPLICATING EACH } \\
\text { BIT ONCE TO GET } \\
\text { THE CIPHERTEXT }\end{array}$ & $\begin{array}{l}1111111100111111 \\
11000011110000\end{array}$ & 10000 & & 11100 & & & & \\
\hline
\end{tabular}

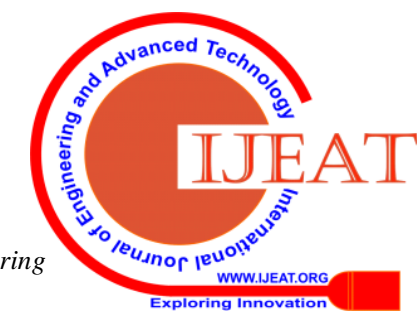




\subsection{DECRYPTION:}

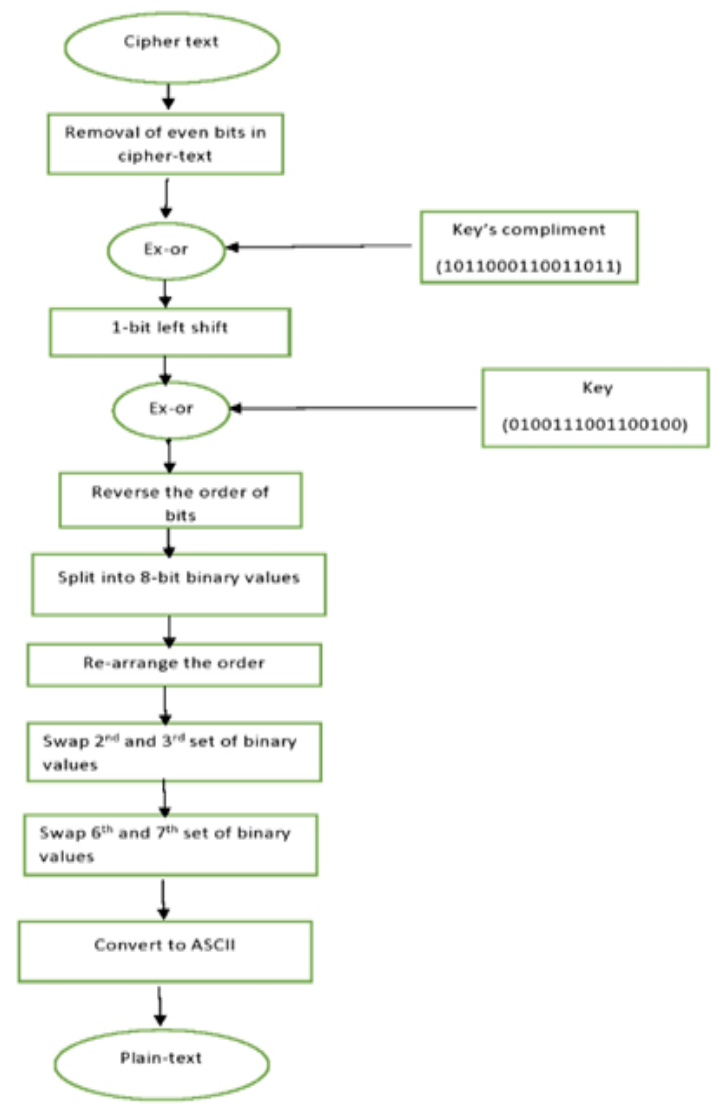

Fig 18 : Flow Chart - Decryption

Step 1: The 32-bit cipher text is obtained, in which the even number of bits are removed.

Step 2: The data is divided into four sets of 16 bit values.

Step 3: The key's compliment value is obtained which is ex-ored with step 2.

Step 4: Perform 1-bit left shift with the result obtained from step 3.

Step 5: Ex-or the key value with the left shifted bits.

Step 6: Reverse the order of bits with the result from step 5.

Step 7: Split into 8 sets of 8-bit binary values.
Step 8: Swap the 2nd and 3rd byte values and 6th and 7th byte values.

Step 9: Convert into corresponding ASCII from the result obtained in step 8.

Step 10: The 8-character plain text is obtained

\begin{tabular}{|c|c|c|c|c|c|c|c|c|}
\hline CIPHFR TFXT & \multicolumn{8}{|c|}{ 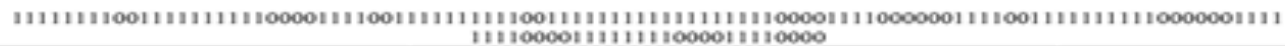 } \\
\hline $\begin{array}{c}\text { REMOVAL OF } \\
\text { SUCCESSIVE EVEN } \\
\text { MIYS }\end{array}$ & \multicolumn{2}{|c|}{1111011111001101} & \multicolumn{2}{|c|}{1111011111111100} & \multicolumn{2}{|c|}{$\underset{0}{11000110111100}$} & \multicolumn{2}{|c|}{1111001111001100} \\
\hline KFY'S COMPLIMENT & $\begin{array}{c}1011000110011 \\
011\end{array}$ & & & & & & & \\
\hline $\begin{array}{c}\text { XOR-INO THE } \\
\text { OBTAINFD BIT WITH } \\
\text { THE AMOVE I'S } \\
\text { COMPLIMENT OF THE } \\
\text { KFY }\end{array}$ & $\begin{array}{c}0100011001010 \\
110\end{array}$ & $\begin{array}{c}01000110011001 \\
11\end{array}$ & $\begin{array}{c}011011101100 \\
\text { o11 }\end{array}$ & $\begin{array}{c}0100001001010 \\
111\end{array}$ & & & & \\
\hline 1-BIT LEFI SHIFI & $\begin{array}{c}1000110010101 \\
100\end{array}$ & $\begin{array}{c}10001100110011 \\
10\end{array}$ & $\begin{array}{c}1110111011000 \\
110\end{array}$ & $\begin{array}{c}1000010010101 \\
110\end{array}$ & & & & \\
\hline $\begin{array}{l}\text { XOR-ING THE LEFT } \\
\text { SHIFIFD BIT WITH } \\
\text { THF KFY }\end{array}$ & $\begin{array}{c}1100001011001 \\
010\end{array}$ & $\begin{array}{c}11000010101010 \\
10\end{array}$ & $\begin{array}{c}1010001010100 \\
010\end{array}$ & $\begin{array}{c}1100101011001 \\
010\end{array}$ & & & & \\
\hline REVERSE THE ORDER & $\begin{array}{c}010001101000 \\
011\end{array}$ & $\begin{array}{c}01001010101000 \\
\text { 011 }\end{array}$ & $\begin{array}{c}0100010101000 \\
101\end{array}$ & $\begin{array}{l}\text { 0100011101010 } \\
\text { 011 }\end{array}$ & & & & \\
\hline $\begin{array}{l}\text { SPLIT ENTO } 8 \text { BITS } \\
\text { EACH }\end{array}$ & 01010011 & 01000011 & 010010101 & 0100001 & $\begin{array}{c}010001 \\
01\end{array}$ & $\begin{array}{c}010001 \\
01\end{array}$ & 0101001 & ${ }_{11}^{01000}$ \\
\hline 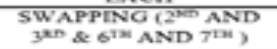 & 01010011 & 010010101 & 01000011 & 0100001 & $\begin{array}{c}010001 \\
01\end{array}$ & $\begin{array}{l}010100 \\
11\end{array}$ & $\begin{array}{c}0100010 \\
1\end{array}$ & $\begin{array}{c}010100 \\
11\end{array}$ \\
\hline ASCII & 83 & 85 & 67 & 67 & 69 & 83 & 69 & 83 \\
\hline PLAINTEXT & $\mathbf{s}$ & $\mathrm{u}$ & c & c c & $\mathbf{F}$ & s & E & s \\
\hline
\end{tabular}




\subsection{Symmetric Random Biometric Key-Features}

The proposed algorithm will be several times faster than the existing algorithm.

$>\quad$ This algorithm is safe against unauthorized attacks and runs faster than the popular existing algorithm.

With this new approach we are implementing a technique to enhance the security level of this algorithm and further reduce the time for encryption and decryption.

\section{RESULTS AND DISCUSSIONS}

Comparison is made between the AES algorithm and SRBK algorithm. Memory occupied by SRBK is several times lower than AES algorithm. The encryption time (time taken by the algorithm to convert from plain text to cipher text) is calculated for both the algorithms. Since the number of steps for encryption and decryption is less for SRBK, the overall encryption and decryption time is lesser than AES. The throughput is obtained based on the encryption time. It shows the speed of encryption and decryption. The speed at which the total plaintext encrypted divided by encryption time. The throughput is higher for SRBK compared to AES.

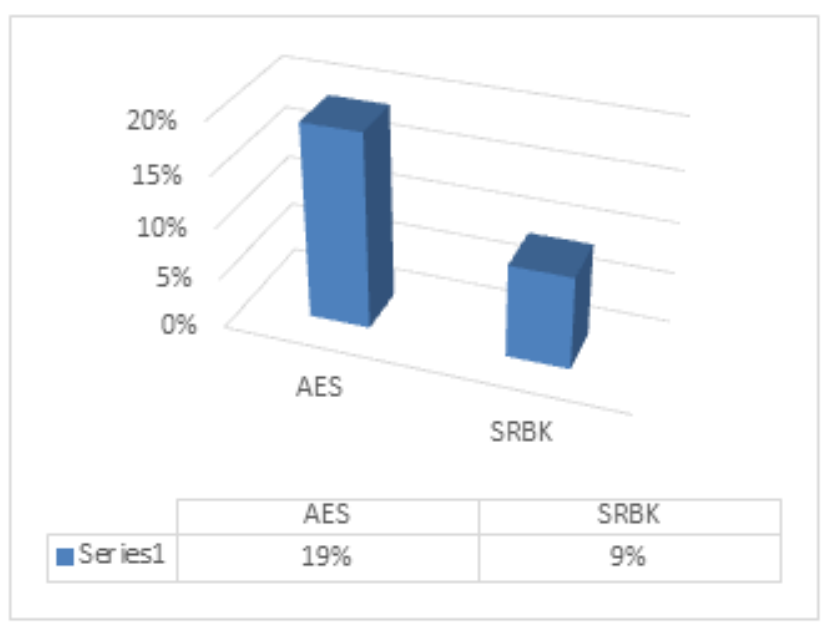

Fig 19: Memory occupied by AES and SRBK

\begin{tabular}{|c|c|c|c|c|c|}
\hline $\begin{array}{l}400 \\
200 \\
0\end{array}$ & 2 & 3 & 4 & 5 & \\
\hline & 1 & 2 & 3 & 4 & 5 \\
\hline INPUT DATA & 50 & 60 & 100 & 240 & 320 \\
\hline AES & 57 & 39 & 91 & 113 & 165 \\
\hline SRBK & 29 & 36 & 48 & 76 & 88 \\
\hline
\end{tabular}

INPUT DATA DAES DSBK

Fig 20: Input data in $\mathrm{Kb}$ and $\mathrm{CPU}$ process time for encryption in milliseconds

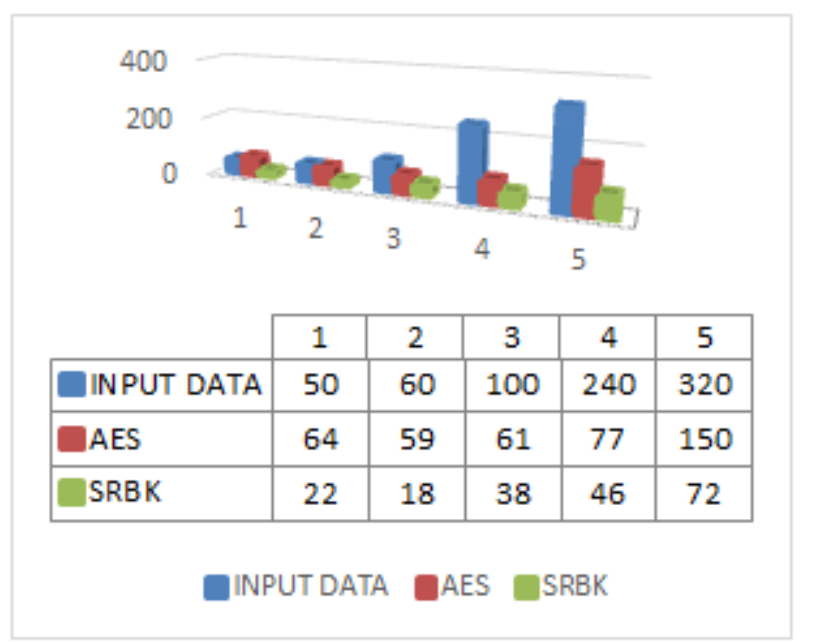

Fig 21: Input data in $\mathrm{Kb}$ and $\mathrm{CPU}$ process time for

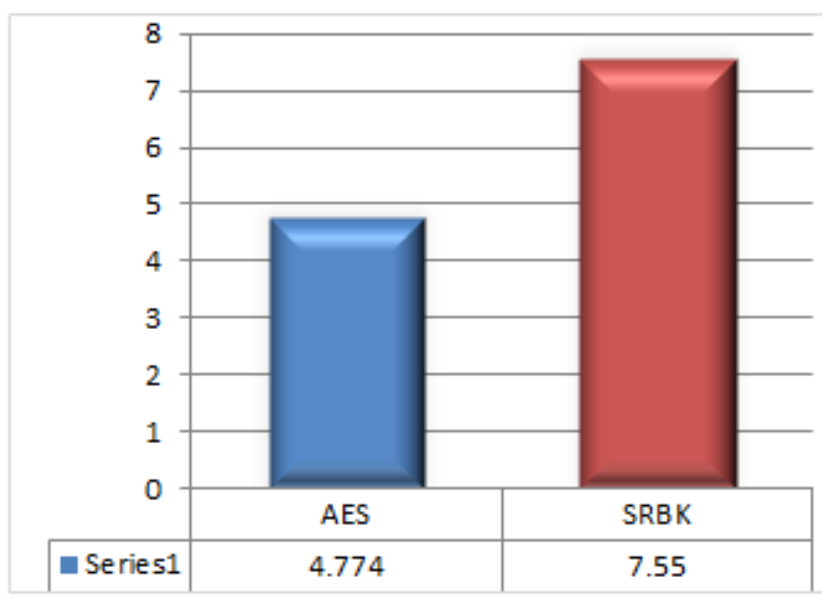

Fig 22: Throughput (Mb/sec)- ENCRYPTION Decryption in milliseconds

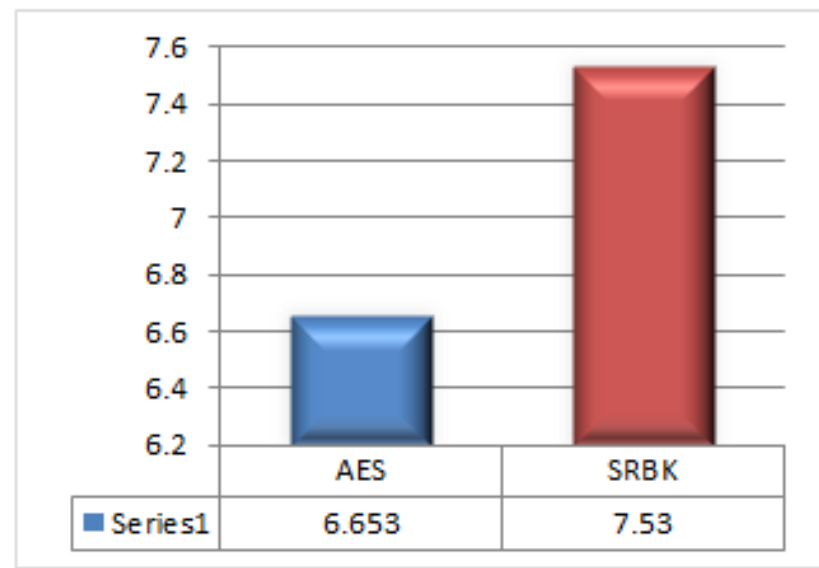

Fig 23: Throughput (Mb/sec)- DECRYPTION

\section{CONCLUSION AND FUTURE WORK}

Thus the proposed algorithm occupies less memory and encryption and decryption time proving it is better than existing encryption algorithm. The biometric key used for encryption and decryption is flexible and the number of bits can be changed based on the plain text used. We also say that the key is secure since it is generated from our own biological trait. 
The future work can be extended with the additional novel method with increase number of rounds for better security and the increased key length for encryption and decryption. Additional algorithm can also be used for comparison.

\section{REFERENCES}

1. "A Comparative Survey on Symmetric Key Encryption Techniques"- Monika Agrawal, Pradeep Mishra, International Journal on Computer Science and Engineering (IJCSE), Vol. 4 No. 05 May 2012, ISSN 0975-3397,Page no.877-882.

2. "Advanced Encryption Standard (AES) Algorithm to Encrypt and Decrypt Data" -Ako Muhamad AbdullahResearch gate- Publication Date: June 16, 2017

3. XAdvanced Encryption Standard - Tutorialspoint https://www.tutorialspoint.com/cryptography/advanced_ encryption_standard.html

4. "A Survey on Cryptography Algorithms" Omar G. Abood, Shawkat K. Guirguis-International Journal of Scientific and Research Publications, Volume 8, Issue 7, July 2018495 ISSN 2250-3153

5. "A Survey on Common Symmetric Encryption Algorithms" Arvind Kumar Sharma and Hitesh SharmaInternational Journal of Engineering Research \& Technology (IJERT) IJERT ISSN: 2278-0181 Vol. 3 Issue 12, December-2014.

6. "A SURVEY ON ENCRYPTION ALGORITHMS USING MODERN TECHNIQUES" Venkat Prasad.K, S. Magesh,- International Journal of Pure and Applied Mathematics Volume 117 No. 16 2017, 673-678.

7. "A Survey on the Cryptographic Encryption Algorithms" -Muhammad Faheem Mushtaq, Sapiee Jamel, Abdulkadir Hassan Disina, Zahraddeen A. Pindar, Nur Shafinaz Ahmad Shakir, Mustafa Mat Deris-(IJACSA) International Journal of Advanced Computer Science and Applications, Vol. 8, No. 11, 2017.

8. "Encryption Algorithms: A Survey"-Swathi S V, IILahari P M, IIIBindu A Thomas-International Journal of Advanced Research in Computer Science \& Technology (IJARCST 2016)- Vol. 4, Issue 2 (Apr. Jun. 2016).

9. Formulation of Ear Biometric Key with an Eminent Noise Immune Filter to Provide High Security in Authentication -Ms.S.Pavithra, ,Dr.P.Muthukannan, Mr.V.Prabhakaran, Jour of Adv Research in Dynamical \& Control Systems, Vol. 10, 07-Special Issue, 2018

10. "Foundations of Computer Security" Lecture 52: DiffieHellman Key Exchange Dr. Bill Young Department of Computer Sciences University of Texas at Austin.

11. "Generation of Cryptographic Keys from Personal Biometrics: An Illustration Based on Fingerprints" By Bon K. Sy and Arun P. Kumara Krishnan.

12. Lecture Notes on "Computer and Network Security" by Avi Kak (kak@purdue.edu)

13. "Performance Analysis of AES and DES Cryptographic Algorithms on Windows \& Ubuntu using Java", Shraddha Dadhich, International Journal of Computer Trends and Technology (IJCTT) - Volume 35 Number 4 - May 2016.

14. "Performance Analysis of AES, DES and RSA Cryptographic Encryption Algorithms: A Novel Study"Nitin Arora, Kritika Metha, Km. Anjali, Manisha Bhatt, Km. Aradhana, Krishan Chandra Mishra, Mamta Martolia-International Journal of Electrical Electronics \& Computer Science Engineering Volume 3, Issue 3 (June, 2016) | E-ISSN : 2348-2273 | P-ISSN : 2454-1222.

15. "SURVEY ON DIFFERENT TYPE OF ENCRYPTION ALGORITHM'S"- Namdev Choure, Prof. Shrikant Dhamdhere-open access international journal of science and engineering-|| Volume 3 || Special Issue 1 || March 2018 